for the streamer must remain a streamer, the intensity of the light must not be radically changed and there must be no marked change in its colour. That there should be two such processes is very unlikely on general principles. No suggestion has been made regarding this second process except that it may be due to a high electrical field in the lower atmosphere produced by the aurora itself; but instrumental observations have shown that such high electrical fields do not accompany auroras. Further, no electrostatic field in air at atmospheric pressure can be made in the laboratory to give a glow throughout an extensive region; the highest field attainable only produces localised brush discharges or actual disruptive sparks which are not remotely like the glow of an aurora.

The second argument is based on the principles of perspective. Practically all the observers report that the low auroras look exactly like the normal auroras: they move in the same way, they appear both as streamers and as diffuse glows, they are of the same colour. No difference in breadth of streamer, rapidity of motion, intensity of light or colour is remarked upon. In fact, it is because the low aurora looks like and behaves like the high aurora that their identity is so strongly affirmed. All this is contrary to the laws of perspective. It is generally admitted that the normal aurora occurs in the upper atmosphere at a height of at least $80 \mathrm{~km}$., so that the average distance from the observer must be something like a hundred miles. If such an aurora were suddenly transferred to the neighbourhood of the observer, it certainly would not look exactly the same as it did when it was a hundred miles away. Thus the opinions so strongly held by the observers that they have seen auroras at ground level exactly like the ordinary high auroras is the strongest evidence that could possibly be given against their conclusions.

The third line of attack is to show that all the reported cases of low aurora are optical illusions. The darkness necessary for the aurora to be seen at all makes illusions easy, especially if there is a moon, for moonlight illuminates clouds and snow ridges with an intensity comparable with that of an aurora. Auroras seen between gaps in clouds or between trees when the whole landscape is dark look as though they are in front of the clouds or trees. The aurora appears in the sky simply as light masses and the observer has absolutely no criteria by which to determine the distance; but with ordinary lights their brightness and the sharpness with which they can be seen are the two factors on which judgment of distance is chiefly based. The aurora varies greatly in intensity and without exception the most brilliant auroras consist of rapidly moving, very sharply defined streamers, either in the form of curtains with clear-cut 'folds' or as long narrow shafts with relatively sharp edges. It is therefore not surprising that these auroras appear to be much nearer than those which appear as irregular ill-defined arches and clouds. Many so-called low auroras are simply parts of haloes round the moon or are due to the illumination of fog banks or snow surfaces in bright moonlight.

In concluding his article, Dr. Simpson says that it is not possible to bring the same type of argument against the sound of an aurora as against its low position; but naturally, if the aurora is confined to the high atmosphere, scunds are unlikely. He considers that the observed sounds are psychological, being due to the natural association of sound with the rapid movement of the streamers and the waving of the 'draperies'.

\title{
Obituary
}

\section{Mr. Charles S. Carter}

$\mathrm{T}$ HW death of Charles S. Carter, curator of the Museum of the Louth Naturalists', Antiquarian and Literary Society, and president of the Lincolnshire Naturalists Union in 1928 and 1929, at the age of sixty-seven, took place at Louth (Lines) on April 14. In addition to being curator of the Museum, Mr. Carter was joint honorary secretary of the Society and conchological secretary of the Lincolnshire Naturalists Union, as well as a member of the Lincolnshire Archæological Society.

$\mathrm{Mr}$. Carter belonged to the distinguished band of self-taught amateur scientific investigators, to which local archæology and natural history in Great Britain are so deeply indebted. Not only by their individual labours, but also by the enthusiasm with which they have inspired others, they have kept alive a tradition of local interest and research, in which Great Britain stands almost, if not quite, alone.

Born in $\mathbf{1 8 6 6}$ at East Torrington, Mr. Carter was educated for a short time at elementary schools, and then began work in the fields at the age of nine. He was later apprenticed to a cordwainer and worked as a cobbler for the remainder of his life. His interest in archæology and natural history began when he took up his residence: in Hampshire, under the influence of Dr. S. Andrews of Basingstoke, with whom he traced the Rornan road through Pamber Forest aud was a close observer of the excavation of the neighbouring Roman city of Silchester. On removing to Kent, he became associated with the late Benjamin Harrison and Dr. Lewis Abbott between the yo:ars 1893-1896 in the collection of eoliths. The period of his greatest activity, however, began wher he returned to Louth in 1898. Among other achicvements, he discovered the neolithic settlements at Tathwell and Kelstern, recorded several botanical and entomological species for the first time in the county, and found a chalk fossil, Tylopora lorea, Lang, which was new to science. Mr. Carter was a frequent contributor to the Naturalist and the Proceedings of the Lincolnshire Naturalists Union. 